䅈

\title{
BRUNO LATOUR E A GEOGRAFIA: O TERRITÓRIO DESDE UMA PERSPECTIVA NÃO MODERNA*
}

- DAVID ALEJANDRO RAMÍREZ PALACIOS 1

${ }^{1}$ Historiador - Universidade Nacional da Colômbia. Mestre em Geografia Humana - Universidade de São Paulo. Doutor em Geografia Humana - Universidade de São Paulo. Pesquisador Pós-doutoral - PPHIST-Universidade Federal do Pará. E-mail para contato: daramirezp@gmail.com

Recebido em: $18 / 07 / 2019$

Aprovado em: 10/11/2019

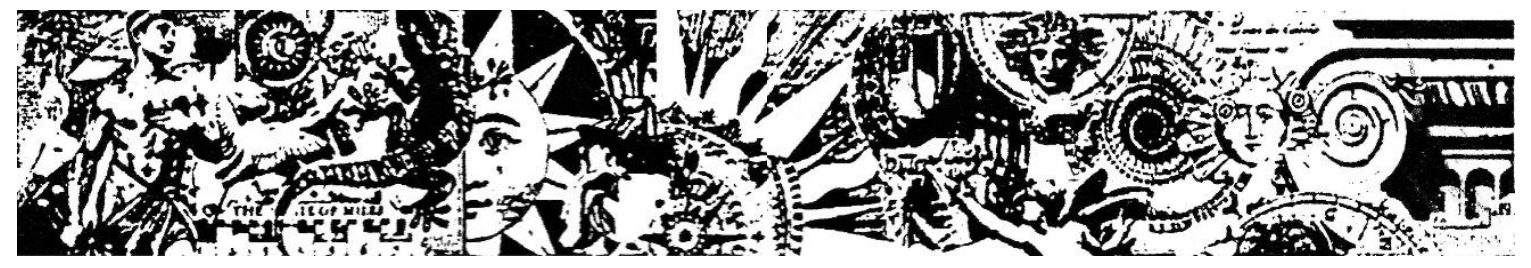

Resumo: No que concerne à geggrafia, à história da geografia e à história da cartagrafia, a obra de Bruno Latour atinge pontos sensíveis que vale a pena examinar. Debates epistemológicas clássicas e caras à geografia são percebidas de outra maneira quando vistos desde uma perspectiva nãa modernista. No funda, a que o presente artigo pretende argumentar é que a geografia tem sida historicamente a ciência par excelência das relações entre entidades heterogêneas e interdependentes, apesar de ter sido obrigada pela "Constituiçãa Moderna" a exprimir-se dicotomicamente. Mas não apenas a pensamenta de Bruno Latour possui uma mensagem libertadora para a geagrafia, senão que, a tradiçãa gegráfica, neste casa particular a geggrafia política através do conceito de território, tem também como contribuir às teorias relacionais pós-representacionais.

Palavras-chave: Bruno Latour. Geggrafia; história; cartografia; território; modernismo; rede 


\section{BRUND LATOUR AND GEQGRAPHY: TERRITORY FRDM A NDN-MDDERN VIEW}

ABSTRACT: AS FAR AS GEOGRAPHY, THE HISTORY DF GEOGRAPHY AND THE HISTORY OF CARTOGRAPHY IS CDNCERNED, BRUND LATOUR'S WORK TOUCHES SENSITIVE PDINTS THAT WORTH EXAMINATION. EPISTEMULOGICAL DEBATES CLASSIC AND CHERISHED bY geDGRAPHY ARE PERREIVED IN A DIFFERENT WAY WHEN GBSERVED FROM A NDN-MODERNIST VIEW. IN THE END, WHA THE PRESENT PAPER ATTEMPTS TO STRESS IS THAT GEQGRAPHY HAS BEEN HISTORICALLY THE SCIENCE PAR EXCELLENCE DF RELATIONSHIPS BETWEeN hETERDgeNEDUS AND INTERDEPENDENT ENTITIES, DESPITE OF WHICH HAS BEEN CDMPELLED BE THE "MODERN CONSTITUTION" TO EXPRESS ITSELF THRDUGH DICHOTOMIES. BUT NOT ONLY LATOUR'S THOUGHT HAS A LIBERATING

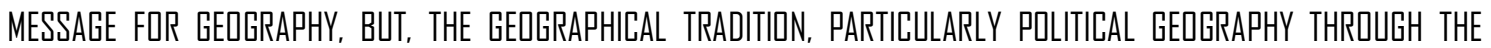
CONCEPT OF TERRITORY, IS ABLE TO CDNTRIBUUTE IN ITS TURN TO RELATIONAL PDST-REPRESENTATIONAL THEDRIES. KEYWDRDS: BRLIND LATDUR; GEOGRAPHY; HISTORY; CARTOGRAPHY; TERRITORY; MDDERNISM; NETWORK

\section{BRUND LATDUR Y LA GEOGRAFÍA: EL TERRITTRII DESDE UNA PERSPECTIVA ND-MDDERNA}

RESLIMEN: EN LO QUE CONCIERNE A LA GEOGRAFÍA, A LA HISTORIA DE LA GEOGRAFÍA Y A LA HISTORIA DE LA CARTOGRAFÍA, LA OBRA DE BRUND LATOUR TUCA PUNTOS SENSIBLES QUE VALE LA PENA EXAMINAR. DEBATES EPISTEMIĹGICUS CLÁSICUS Y CARDS A LA GEOGRAFÍA SON PERCIBIDOS DE QTRA MANERA CUANDO VISTOS DESDE UNA PERSPECTIVA ND-MDDERNISTA. EN EL FONDO, L Q QUE EL PRESENTE ARTíCULD PRETENDE ARGLMENTAR ES QUE LA GEOGRAFÍA HA SIDO HISTÓRICAMENTE LA CIENCIA POR EXCELENCIA DE LAS RELACIONES ENTRE ENTIDADES HETERDGÉNEAS E INTERDEPENDIENTES, A PESAR DE LO CLAL HA SIDU

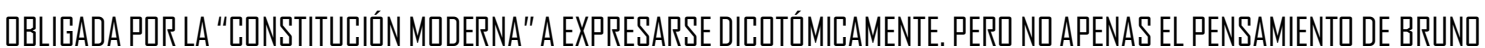

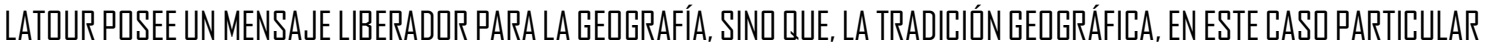

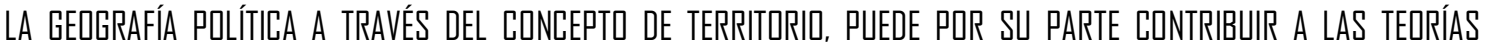
RELACIONALES POS-REPRESENTACIONALES.

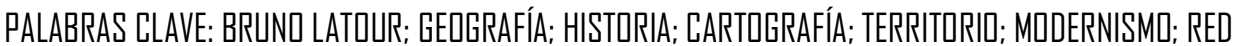

\section{Introdução}

Bruno Latour é ao mesmo tempo um autor muito conhecido e muito pouco conhecido. Nos últimos anos tem de fato aumentado o interesse por seus escritos em diversas áreas do conhecimento. No entanto, não é raro encontrar apropriações muito parciais do seu pensamento que chegam a desfigurá-lo, como também é comum encontrar a esse respeito claros erros de interpretação e até de tradução, fundamentalmente quando se tenta, inclusive por motivos psicológicos, enquadrar seus conceitos dentro do paradigma modernista que a sua teoria nega.

O presente trabalho procura a interseção de duas linhas de discussão: uma provêm dos estudos das ciências, e a outra provêm da geografia política. Tentarei explicar como o conceito de "rede" da linha de pesquisa que vem trabalhando estimulada pelo pensamento de Bruno Latour, apesar do que alguns poderiam pensar pelo nome, é um conceito cheio de materialidade - daquela materialidade de que tanto gostamos os geógrafos. Tentarei mostrar como a linha de pesquisa em formação territorial pode 
beneficiar-se e fortalecer-se com conceitos daquela teoria, sem perder a figura e sem abandonar o núcleo estatal do nosso conceito central (o território). E, ao mesmo tempo, tentarei refletir acerca da maneira em que o conceito de território da tradição da geografia política, que procura entender a ação espacial do Estado, pode complementar a Actor-Network Theory, ou "teoria do ator-rede", com a sua experiência e sensibilidade nos estudos de formação territorial e na abordagem de conflitos involucrando espacialidade e identidade.

Como tenho proposto nos meus trabalhos de mestrado (RAMÍREZ PALACIOS, 2010) e doutorado (RAMÍREZ PALACIOS, 2015), dos quais o presente artigo é um dos resultados, pode entender-se a história territorial como o estudo simultâneo da história das ciências geográficas e cartográficas; da geografia política — ou seja, as estratégias e ações espaciais dos Estados em relação com outras formas de espacialidade; e dos processos de geração e espacialização de identidades coletivas.

\section{A Actor Network Theory (ANT)}

Resultado de uma confluência entre os Science Studies, dedicados à observação das práticas científicas e à análise das redes técnico-científicas, a antropologia comparativa, que constata a singularidade do pensamento dicotômico moderno, e a observação das práticas dos movimentos ambientalistas, acostumados a enfrentar a todo momento controvérsias envolvendo complicados arranjos de atores múltiplos e heterogêneos, a Actor-Network Theory (ANT) propõe entender o 'social' em termos de 'associações', em lugar de defini-lo como uma dimensão, âmbito, camada ou fatia da realidade (LATOUR, 2005). Dentro destas associações, ou networks, caberiam não apenas os seres humanos, mas também a enorme diversidade de entidades não humanas que compõem o mundo ou o 'coletivo' (LATOUR, 2004a). No final das contas, não haveria 'sociedade’ por um lado e 'natureza' por outro, nem 'sujeitos' ou 'objetos' puros, mas seres “híbridos” (LATOUR, 1993), que seriam efeitos ou estados das interações entre entidades heterogêneas. Nesse sentido, trata-se de uma teoria antiessencialista, que procura, como princípio, evitar a reificação e a coisificação.

Não se deve confundir o conceito de rede de Latour et al com outros conceitos de rede. "Network", desde o ponto de vista desta teoria, não alude apenas às dinâmicas de fluxos ou às lógicas reticulares (como redes comerciais ou redes de transporte, ou a internet), mas é compreendida como um sinônimo de "realidade”, "mundo", "cosmos", “ecúmeno” ou “coletivo” (LATOUR, 1998). 
Boa parte desta teoria é uma resposta (pretensamente uma saída) ao debate entre "realistas" e "construtivistas sociais" ocorrido no final do século XX, conhecido como a "Guerra das ciências" (LATOUR, 2001). Conceitos como "rede", "ator", "híbrido" ou "coletivo", entre outros, pretendem substituir os antigos de "sociedade" e "natureza", "realidade" e "consciência", "sujeito" e "objeto" e outros equivalentes da longa lista de dicotomias que caracteriza o pensamento moderno.

Latour, decerto, não foi o primeiro nem o único autor que percebeu limitações no paradigma dicotômico e essencialista constitutivo da modernidade. No entanto, é muito comum encontrar autores que, apesar de experimentar desconforto com a forma dicotômica estabelecida para descrever o mundo, acabam recorrendo a mais e mais distinções dicotômicas. Latour e companhia, em meu ponto de vista, têm o mérito de ter procurado desenvolver um vocabulário não dicotômico com o qual se pode descrever a realidade-rede, vocabulário que, se bem que estranho e um pouco cacofônico — sendo este, talvez, um dos preços a pagar pelo abandono do paradigma moderno, pelo menos em um primeiro momento -, encontra-se aberto à discussão e em constante desenvolvimento.

Em todo caso, dito vocabulário não precisa ser utilizado nos resultados das pesquisas particulares e concretas, que, penso, podem (e devem) ser apresentados sem necessidade de uma linguagem rebuscada, mas apenas não dicotômica. Neste caso, a $A N T$ funcionaria mais como uma espécie de andaime metodológico, a ser retirado no momento em que a pesquisa se estruturar em torno de seu próprio vocabulário, desenvolvido/apropriado pelo pesquisador ou pesquisadores envolvidos nela.

A $A N T$ não é uma teoria pós-moderna (não se restringe às "representações"; reconhece o multiculturalismo, mas rejeita o "mono-naturalismo"; aceita o poder da linguagem, mas não acredita em "esferas discursivas autônomas"), nem antimoderna (não rejeita a tecnologia, ao contrário). Não é construtivismo social, que explica a ciência a partir de uma suposta "dimensão social" externa a ela, ou que a reduz a lutas de poder ou interesses de classe. Não é epistemologia, mas, de certa forma, ao abandonar a dicotomia epistemologia/ontologia, a redefine. Não é neo-positivismo, nem empirismo naïf, nem uma postura antimétodo (não é uma meta-teoria, nem é antiteoria: convida a desenvolver, utilizar e adaptar teorias no trabalho de tentar dar sentido aos complicados arranjos de seres diversos que conformam o ecúmeno). E também não é dialética, abordagem que consagra o paradigma dicotômico como "contradição fundamental” e "motor da história". A ANT não procura ultrapassar o paradigma dicotômico e 
essencialista constitutivo da modernidade, mas apenas abandoná-lo. Nesse sentido, esta teoria tem sido descrita como "a-moderna" ou "des-moderna".

Sem nenhum vínculo direto com a $A N T$, mas com uma enorme afinidade na prática, o paleontólogo evolucionista e historiador da ciência Stephen Jay Gould, autor de numerosas obras, é, na minha opinião, um escritor consistentemente não dicotômico e antiessencialista. O determinismo biológico ou a dicotomia nature/nurture - tema chave para a geografia - foi abordado por ele em diferentes ocasiões, particularmente no seu conhecido livro acerca do racialismo e a origem do conceito de inteligência como uma entidade unitária, ranqueável, inata e pouco modificável (GOULD, 1996). Nesta obra, Gould ressalta a conexão entre o citado determinismo biológico e alguns dos que considera os "erros mais antigos das nossas tradições filosóficas", sendo estes: o reducionismo (tentar explicar um fenômeno amplo e complexo com base no suposto comportamento determinístico de algumas das suas partes constituintes); a reificação (a propensão a transformar um conceito abstrato em uma entidade unitária); a dicotomização (nosso desejo de particionar realidades contínuas e complexas em divisões por dois); e a hierarquização, a nossa inclinação a ordenar itens ranqueando-os em séries lineares de crescente valor.

Estas advertências de Gould concordam, acredito, com a definição negativa da $A N T$ — do que ela "não é" —, dada aqui até agora. ${ }^{2}$ De maneira afirmativa, pode-se dizer que a dita teoria - e a tradição geográfica tem familiaridade com este tipo de formulação, mesmo que presa nas exigências dicotomizadoras do modernismo (RAMÍREZ PALACIOS, 2014) - interessa-se pelo estudo, descoberta e compreensão de correlações entre entidades heterogêneas. Seu ponto de partida são as controvérsias técnicocientífico-político-ético-estéticas que nos rodeiam, nas quais estamos envolvidos e que fazem parte de nós. O ponto de chegada não é conhecido de antemão.

Por outro lado, vale relembrar que Bruno Latour ilustra os conceitos clássicos de “móvel imutável” e de "centro de cálculo" utilizando uma imagem cartográfica (LATOUR, 2015). Também, mais recentemente, este autor tem ingressado diretamente no território do pensamento geográfico (NOVEMBER; CAMACHO-HÜBNER; LATOUR, 2013), acredito que, até agora, sem resposta da parte dos teorizadores e historiadores da geografia.

\footnotetext{
2 Como hipótese para uma possível pesquisa futura: quem liga Bruno Latour, Stephen Jay Gould e certas partes da obra de Milton Santos é o filósofo Alfred North Whitehead.
} 
Ao tomar como base teórico-metodológica a $A N T$, meu objetivo é colocar em diálogo esta linha de pesquisa com a tradição da geografia política, em particular com os estudos em história territorial.

Não pretendo no presente artigo tentar um resumo da trajetória das linhas de pesquisa associadas a Bruno Latour: há uma longa trajetória desde os "estudos sociais da ciência” —que é uma das suas matrizes, apesar dos posteriores ataques a esta linha por parte do mesmo Latour (Cf. o famoso debate Bloor-Latour: BLOOR, 1999a, b; LATOUR, 1999) até a atual "cartografia de controvérsias" (LATOUR, 2007) e as chamadas "digital humanities", passando pelos "estudos da ciência" e posteriormente a “ANT": há excelentes textos de balanço e introdução ao tema (como os de J. S. Dolwick (DOLWICK, 2009) e Tommaso Venturini (VENTURINI, 2010a, b)), mas deve mencionar-se em particular o trabalho de 2005 de Bruno Latour intitulado Reassembling the Social: An introduction to Actor-Network Theory (LATOUR, 2005), publicado em português em 2012 com o título de Reagregando o Social: Uma introdução à teoria do AtorRede (LATOUR, 2012).

Neste trabalho Latour procura apresentar para um público amplo tanto os conceitos centrais como as caraterísticas fundamentais do tipo de abordagem desenvolvido durante anos nesta área de pesquisa. Latour parte da distinção entre dois sentidos do "social". Em primeiro lugar estaria o social entendido como um campo, um área, um nível, uma fatia, uma camada ou uma dimensão da realidade (realidade que teria então desta forma um ou mais componentes "não sociais") e nesse sentido utilizado como adjetivo (geografia "social", por exemplo), ou como um "estado de coisas" que explica outro (a história "social” da ciência, por exemplo"); e, em segundo lugar, no que segundo Latour seria o sentido original do termo - e que este autor propõe recuperar - estaria o "social” entendido como associações ou "ensamblagens". Mas quem participa destas associações? Segundo Latour, e isto acredito que constitui um dos aspectos principais desta teoria, uma rede ou network de elementos heterogêneos, mas que não abrange apenas aos seres humanos e seus projetos e conflitos, mas também os elementos "não humanos" que compõem o mundo junto conosco — sendo muitos deles as nossas próprias criações tecnológicas - levando estes em conta não como atores secundários, que estão ali mas não determinam nada, mas como atores protagonistas, os quais são reconhecidos como tendo propriedades e imperativos (e até direitos), isto é, é reconhecida a sua agência. Este compor-o-mundo, ou o coletivo, dessa maneira inter-relacional, faz com que todos os seus elementos, incluindo nós, em certa forma, sejamos híbridos - e 
não apenas "objetos" e "sujeitos", como na epistemologia moderna, que Latour, dissemos, pretende deixar de lado.

A geografia sem dúvida tem uma longa experiência lidando com redes complexas e heterogêneas. Ao fazer história territorial, por exemplo, o pesquisador não raro encontra-se na situação de ter que encontrar sentido e fornecer em uma mesma explicação a natureza das correlações entre questões, processos, elementos, objetos e entidades tão diversos e tão complexos internamente como o clima, a forma das montanhas, a presencia ou a ausência de determinado mosquito transmissor de certa doença, as flutuações do mercado mundial de produtos agrícolas, as políticas territoriais do Estado, a diplomacia, a produção de mapas e livros de geografia, os partidos políticos, os missionários, os indígenas, as bacias hidrográficas, as ideologias geográficas, a miscigenação. A agencia, a capacidade de fazer diferença, não se encontraria em um lugar só, nem apenas em um tipo de entidade, não seria um atributo exclusivo dos "sujeitos", como afirmam as tendências possibilistas ou voluntaristas, nem tampouco exclusivo dos “objetos", como o seria para as tendências deterministas ou estruturalistas, nem também se trataria aqui de uma espécie de dialética: a agencia seria uma propriedade das associações. A pergunta seria acerca de como essa agência é distribuída entre os atores associados e acerca das espacialidades e temporalidades que surgem desta distribuição. Desde meu ponto de vista, esta perspectiva pode ajudar a superar uma espécie de ansiedade sofrida por uma parte dos geógrafos, que receiam ser chamados de deterministas. Na minha opinião, a $A N T$ oferece à geografia uma forma segura de fazer o que sempre gostou de fazer (estudar inter-relações complexas entre elementos heterogêneos de diversa qualidade e procedência), sem se preocupar por essa acusação. Acredito que desde este ponto de vista a geografia poderia definir-se em um sentido amplo como a ciência da espacialidade das agências.

Não seria possível aqui tampouco tentar uma resenha histórica da geografia política. Também falta até hoje uma avaliação sistemática das diferentes propostas que, dentro da geografia, tentaram nos últimos anos explorar possíveis entrecruzamentos entre esta disciplina e a $A N T$ (LAW; MOL, 200 1; MURDOCH, 1998; PAINTER, 2006; THRIFT, 2008; WHATMORE, 2002). No entanto, vale a pena fazer uma menção: uma das introduções mais conhecidas e tal vez mais interessantes à geografia política é o livro de 2002 do pesquisador John Agnew intitulado Fazendo geografia política (AGNEW, 2002). Neste texto não apenas fica retratada a trajetória dos conceitos centrais desta disciplina, assim como as suas diferentes tendências metodológicas em diferentes épocas, 
mas também a diversidade de problemas e conflitos que é capaz de abordar com originalidade e efetividade. No entanto, desejo ressaltar o comentário consignado nessa obra acerca da $A N T$. Segundo Agnew, no seu elenco de diferentes concepções do “político", baseando-se na versão dela fornecida pelo pesquisador Nigel Thrift, nesta teoria o poder "pode pensar-se como algo implícito nas práticas de atores-rede que conectam, entranham, e dão forma a todas as atividades sociais":

$\mathrm{Na}$ assim chamada teoria do ator-rede, o poder é o recurso que as redes proveem aos atores (humanos, animais e tecnológicos) para que os propósitos econômicos, associativos e políticos das redes possam funcionar. As práticas relacionais e as performances que geram redes políticas, assim, constituem o político nesta solução à restrição do político do reino do tudo para algo mais específico. ("In so-called actornetwork theory, power is the resource that networks provide to actors (human, animal and technological) to make networks serving business, associational, and political purposes work. The relational practices and performances that make up political networks, therefore, constitute the political in this solution to the narrowing of the political from the realm of everywhere to something more specific". AGNEW, 2002, p. 23)

Logo depois desta apresentação da $A N T$, Agnew levanta um questionamento que considero singularmente interessante: "se não é isto retornar a uma compreensão substantivamente liberal do político, é uma questão em aberto". Não possuo uma resposta completa a esta pergunta. No entanto, no meu conceito, ao estender o "liberalismo", que apenas reconhecia indivíduos, aos atores-rede - que não são exatamente indivíduos — o liberalismo fica substancialmente transformado.

O presente artigo, com base nestas questões, constitui um exercício de exploração experimental, provisional, animado por uma motivação unificadora, que procura o mútuo fortalecimento das teorias relacionais e da geografia política - que espero não seja injusto com nenhuma das duas tradições e que talvez possa chegar a ser estimulante para outros pesquisadores.

\section{A Espacialidade das Redes: Móbiles imutáveis e centros de cálculo}

Como fica a $A N T$ em chave espacial, geográfica ou territorial? Examinemos um tex to clássico de Bruno Latour, em que este autor fornece alguns conceitos de grande 
importância para nossa investigação. Neste texto, intitulado "Cognição e visualização: pensando com olhos e mãos" (LATOUR, 2015), Latour introduz uma imagem cartográfica para levantar a sua questão:

Um exemplo ilustrará o que quero dizer. As viagens de La Pérouse pelo Pacífico para Luís XVI com a missão explícita de trazer de volta um melhor mapa. Um dia, ao chegar no que ele chama Sacalina, encontra-se com chineses e procura aprender deles se é Sacalina uma ilha ou uma península. Para a sua grande surpresa os chineses entendiam geografia bastante bem. Um velho levanta-se e desenha um mapa da sua ilha na areia com a escala e os detalhes necessitados por La Pérouse. Outro, mais jovem, observa que a subida da maré vai logo apagar o mapa e pega um dos cadernos de La Pérouse para desenhar o mapa de novo com uma pena... (LATOUR, 2015, parag. 14).

Qual é a diferença entre a geografia "selvagem” e a "civilizada”? Segundo Latour, que para o velho a inscrição não interessa, a maré pode apagar, entanto que, para La Pérouse, é o único objetivo da sua viagem. (O jovem da história seria uma espécie de mediador?).

O importante aqui é que a inscrição levantada por La Pérouse, deve retornar para a França - se não, a viagem seria perdida! —, onde, a través de uma longa série de procedimentos e técnicas, vai ser registrada, armazenada, transformada e colocada em comunicação com outras inscrições, levantadas por outros exploradores em outros lugares. A questão então seria de mobilização e acumulação.

Mas o que é o que se movimenta? Os cientistas, os exploradores no caso, deveram desenvolver técnicas e dispositivos para transformar o terreno em traços colocados num plano, assim como para acumular esses traços e dar-lhes sentido. A cartografia e o mapa, numa palavra. A este tipo de dispositivos Latour dá o nome de móbiles imutáveis. Estes devem ser movíveis, lógico, estáveis — não como o traço na areia —, apresentáveis e legíveis (ou seja, convincentes) e combináveis (em cartografia estas combinações conseguem-se muitas vezes através de técnicas matemáticas).

Estes móbiles, para continuar com a caraterização de Latour, devem ter “consistência ótica”, ou seja, uma linguagem homogênea (projeção, longitude e latitude etc.), para poder mudá-los de escala, fazê-los apresentáveis (a um público educado para olhá-los) e recombiná-los à vontade. 
Estes móbiles, mapas neste caso, são definidos por Latour como "novas maneiras de acumular tempo e espaço" - ele está pensando na imprensa (dispositivo capaz de fazer possível a mobilidade e a estabilidade ao mesmo tempo):

Os laços entre diferentes lugares no tempo e no espaço se modificam completamente por esta fantástica aceleração de móbiles imutáveis que circulam em todas partes e em todas direções na Europa. Como mostrado por Ivins, perspectiva mais imprensa mais águaforte é a combinação que realmente importa uma vez que os livros podem carregar com eles imagens realistas daquilo que falam. Pela primeira vez, um local pode acumular outros lugares distantes no tempo e no espaço e apresentá-los sinoticamente ao olho; melhor ainda, esta apresentação sinótica, uma vez reformulada, emendada ou segmentada, pode dispersar-se sem modificação para outros lugares e ficar disponível em outros tempos. (LATOUR, 2015, parag. 30)

Os mapas então seriam desde este ponto de vista dispositivos móbiles, estáveis e dotados de consistência ótica, com os quais seria possível acumular tempo e espaço —e exercer "ação a distância".

Agora, que tem isto a ver com a dominação a grande escala — pois, no caso, tratase de entender a expansão europeia e o eurocentrismo? Como os poucos podem dominar os muitos? (Que pode um império fazer com o mapa, que não pode fazer com o território?). Vejamos algumas das vantagens destes móbiles imutáveis, segundo Latour:

- São móbiles (diferente das montanhas);

- São estáveis (não traços na areia, mas em papel ou em formato digital, em arquivos organizados);

- São planos: podem dominar-se facilmente (com a vista, encima duma mesa, ou numa tela);

- Sua escala pode modificar-se sem mudar as suas proporções internas;

- Podem reproduzir-se a baixo custo;

- Podem reorganizar-se e recombinar-se;

- Podem ser superpostos uns aos outros (e desta forma encontrar patrões, elaborar teorias);

- Podem combinar-se com textos escritos;

- Mas: [...] a última vantagem é a maior. O caráter bidimensional das inscrições lhes permite fundir-se com a geometria. Como vimos para a perspectiva, ao espaço no papel pode dar-se continuidade com o espaço tridimensional. O resultado é que podemos 
trabalhar sobre o papel com réguas e números, mas ainda manipular objetos tridimensionais "lá fora". Melhor ainda, por causa desta consistência ótica, tudo, sem importar de onde vier, pode converter-se em diagramas e números, e podem usar-se combinações de números e tabelas que são ainda mais fáceis de manejar do que palavras ou silhuetas. Você não pode medir o sol, mas você pode medir a fotografia do sol com uma régua. Então o número de centímetros lido pode facilmente migrar por diferentes escalas e prover as massas solares de objetos completamente diferentes. Isto é o que chamo, por falta de um termo melhor, de vantagem de segundo grau das inscrições, ou de mais-valia ganha através da sua capitalização. (LATOUR, 2015, parag. 54) (Não está falando aqui Latour para nós, historiadores do território e das suas ciências?)

Evolutivamente, as inovações que favoreçam essas caraterísticas, tenderão a ser selecionadas por cientistas e engenheiros (e geógrafos e cartógrafos). Pense-se no computador e na digitalização. Mas é suficiente a acumulação de inscrições para exercer poder?

Segundo Latour, não ainda, pois os acumuladores de traços rapidamente ficam inundados por eles (até o pescoço). É preciso antes organizar esses traços em cascatas de inscrições cada vez, mas simplificadas e fáceis, para que, ao final da série, uns poucos elementos possam dominar todos os outros. Esta mudança de escala é o que permite a dominação: "Na nossa cultura 'embaralhar papeis' é a fonte de um poder essencial, que constantemente escapa da atenção devido a sua materialidade ser ignorada” (LATOUR, 2015, p. 71).

Agora, como é possível dominar, ou, em geral, agir sobre aquilo que se encontra longe?

[...] como podem lugares e tempos distantes e exóticos congregar-se em um lugar numa forma que permita que todos estes lugares e tempos sejam representados simultaneamente e que permita as ordens retornarem a seus lugares de origem? Falar em poder é uma tarefa mística e interminável; falar em distância, congregação, fidelidade, sumarização, transmissão etc., é uma tarefa empírica [...]. (LATOUR, 2015, p. 75)

Leia-se este parágrafo em termos de construção imperial ou de afirmação espacial do Estado. Traduzindo: definir "espaço” pode virar uma tarefa mística e interminável; descrever espacialidades ou processos de formação territorial, é uma tarefa empírica. $\mathrm{O}$ Estado, não age à distância, tecendo redes/através de redes? 
Os lugares onde estas inscrições provenientes de distintas procedências são acumuladas, organizadas, processadas, transformadas e colocadas em contato umas com as outras são chamados por Latour "centros de cálculo" (LATOUR, 1987). Nestes lugares, através de ditas manipulações, surgem fenômenos completamente novos, que não são perceptíveis para cada uma das entidades a partir das quais se tomaram as inscrições iniciais. Para Latour, a história destes centros permite compreender como "pessoas insignificantes, trabalhando apenas com papéis e signos, tornam-se os mais poderosos de todos":

Papéis e signos são incrivelmente fracos e frágeis. Eis porque explicar tudo com eles parece risível no começo. O mapa de La Pérouse não é o Pacífico, assim como os desenhos e patentes de Watt não são as máquinas, ou as taxas de câmbio dos banqueiros a economia, ou os teoremas de topologia o "mundo real". O paradoxo é justamente esse. Ao trabalhar apenas com papéis, em frágeis inscrições que são imensamente menos que as coisas das quais foram extraídas, é, todavia, possível dominar todas as coisas e todas as pessoas. O que é insignificante para todas as outras culturas torna-se o mais significante, o único aspecto significante da realidade. Os mais fracos, ao manipular inscrições de todos os tipos exclusiva e obsessivamente, viram os mais fortes. É esta a visão de poder a que chegamos ao seguir este tema da visualização e da cognição em todas as suas consequências. (LATOUR, 2015, p. 80).

\section{O Território como Rede}

Neste ponto acudo a ajuda do pesquisador Joe Painter (PAINTER, 2006, 2009). Este autor explora as possibilidades de convergência de dois conceitos que a princípio parecem opostos: rede e território.

Painter começa por recapitular diferentes posturas recentes a este respeito. A primeira variante segundo ele seria a que considera que as redes substituíram os territórios: "tudo é rede", "território" se correspondia com uma antiga realidade geográfica, mas a nova realidade consiste em redes. Uma variante dentro de esta, segundo Painter, é representada por Bruno Latour: a realidade sempre foi uma rede, mas não tínhamos percebido (sendo este, por sinal, o significado da expressão "jamais fomos modernos"). A este postulado, segundo Painter, poderia responder-se que "o território ainda importa!". Esta resposta, de fato, tem vindo de críticos da ideia da passagem para 
um mundo "sem fronteiras": as redes existem, mas os territórios também, as vezes em relação umas com os outros.

Uma terceira variação seria a que afirma que "a economia funciona como rede, mas a política é territorial", ou seja, que se bem o capitalismo tem conseguido criar redes supranacionais, estas ainda têm que lidar para uma e outra coisa com os "velhos" territórios estatais.

O autor propõe uma quarta maneira de entender a questão: "o território como um tipo especial de rede”. O princípio segundo ele seria o seguinte: o Estado também é rizomático. Painter não clarifica a maneira em que usa este termo, que de fato aparece um pouco repentinamente no texto. No entanto, na minha interpretação, Painter quer dizer que o Estado não é uma entidade monolítica, como às vezes é tratada, mas é também, ele mesmo, uma rede, ou um tipo de rede.

O autor clarifica que considera quatro tipos de rede: as "redes de transmissão" de Catells, pelas quais viajam fluxos e comunicações; as "redes sociais" (ou, digamos, redes entre pessoas); a actor-network de Latour e companhia, que envolve o movimento e a conexão entre coisas materiais (coisas que de fato são consideradas como sendo elas mesmas um efeito das suas interconexões); e finalmente, as "redes topológicas", conceito que o autor insere como uma maneira de pensar acerca das complexas espacialidades das actor-networks. Para Painter, cada uma destas concepções de rede pode associar-se com o conceito de território, obtendo em cada caso resultados distintos: os territórios podem ser nós de transmissão; a territorialidade das relações sociais pode observar-se em termos da sua densidade ou intensidade; e, segundo a teoria da actor-network, os territórios seriam configurações de objetos-em-relação (sendo tanto os objetos quanto as suas configurações constituídas na forma de e através de redes).

Para o autor, finalmente, o território "como tal" (como essência, entendemos), "não existe". Também, não seria um produto das redes, pois isto conservaria as duas como entidades separadas. Para Painter, o território seria, melhor, um efeito das redes:

Como consequência, os espaços que chamamos de territórios são necessariamente porosos, incompletos e instáveis. Eles são constantemente produzidos e realizados por inumeráveis atores humanos e não humanos. O ideal do território político como um espaço contíguo perfeitamente delimitado sobre o qual a soberania (ou outro tipo de autoridade) é exercida suave, contínua e uniformemente pertence ao plano do desejo de Deleuze e Guattari. Desde este ponto de vista "território" e "rede" não são modelos rivais, visões de mundo incomensuráveis, nem mesmo os elementos contraditórios de 
uma relação dialética. Melhor, a configuração de práticas e objetos, energia e matéria que se conhece com o nome de "território" não é nem mais nem menos do que um outro jogo de redes. As configurações tremem e se estabilizam por um tempo e dão a impressão do território. Mas o território não é um tipo de variável independente da vida política e social. Pelo contrário, ele é em si mesmo dependente das conexões rizomáticas que constituem todas as chamadas organizações territoriais, instituições e atores. ("As a consequence the spaces we call territories are necessarily porous, incomplete and unstable. They are constantly produced and accomplished by countless human and non-human actors. The ideal of political territory as a perfectly bounded contiguous space across which sovereignty (or another kind of authority) is exercised smoothly, continuously and evenly belongs to Deleuze and Guattari's plane of desire. In this view, 'territory' and 'network' are not rival models, incommensurable worldviews or even the contradictory elements of a dialectical relationship. Rather, the configurations of practices and objects, energy and matter that go by the name 'territory' are no more and no less than another set of networks. The configurations flicker and settle for a time and give the impression of territory. But territory is not a kind of independent variable in social and political life. Rather, it is itself dependent on the rhizomatic connections that constitute all putatively territorial organizations, institutions and actors". PAINTER, 2009, p. 73).

É possível entender então também o Estado como uma entidade-rede, que age à distância, criando laços —que não necessariamente tem que ser de dominação. Trata-se de abrir a caixa-preta do Estado, de deixar de considerá-lo monoliticamente e seu poder como absoluto (sobre uma determinada área). O Estado está feito de partes, muitas vezes incoerentes, e exerce seu poder sobre o ausente ou o distante através de muitos mediadores, humanos e não humanos. Ao retraçar as ações estatais no espaço (“follow the thing" é uma das frases de batalha desta perspectiva metodológica) surge um tipo de rede, que podemos chamar de território.

Acredito que é possível então definir território como um tipo de rede. E também região, e lugar: são redes de distinta configuração e extensão, mas com muito em comum. Agora, "se tudo é rede, então nada é rede". Justo. Sim, tudo é rede, e tudo acaba se conectando, mesmo que por caminhos muito longos ou intrincados. Mas saber isto não nos explica nada em particular. Estamos interessados em saber/conhecer/entender coisas concretas, como o território. Coisas concretas, para nós, tem forma de redes. Como diferenciarmos a rede-território de outras redes? Como identificamos, reconhecemos ele? 
Todas as definições de território sugerem o domínio, o controle, a restrição do acesso ou a imposição de um comportamento numa determinada área. A vida estaria nesse sentido cheia de territorialidade. A territorialidade não seria sentida só no momento de passar uma fronteira, mas em cada instante da vida, desde acordar até dormir. Não é difícil pensar, por exemplo, numa territorialidade doméstica (na mesa, na casa, na cama).

Mas não é exatamente dessa territorialidade que a geografia política sabe dar conta. Por tradição, por conveniência, por interesse, por lógica, o ator central aqui chama-se Estado. Não se trata de reificar o Estado - todo o contrário! -, nem de “justificar” a sua ação espacial. Também, não que este seja o único ator a considerar. Isto deve ser muito claro. Por princípio, não existem entidades puras, nem independentes, nem isoladas. Cada entidade-rede é definida pelo seu lugar e trajetória com respeito a outras entidades-rede. O que seria do Estado sem outros Estados, por exemplo? Ou sem povo? O Estado existe na medida em que existem outros Estados. O Estado, também, por mais que o pretenda, não é uma entidade monolítica. Tem centros e periferias. Tem lugares em que exerce com maior sucesso a sua ação, e lugares mais difíceis de atingir. Para exercer o seu poder, precisa de uma longa série de intermediários. O Estado está feito de outras entidades-rede que fazem ele realidade. Estas entidades por sua vez também não são puras.

A teoria do ator-rede, nesse sentido, não é possibilista nem determinista, mas procura medir e compreender, num determinado arranjo de coisas (ou num arranjo a determinar) a intensidade e a qualidade das interações entre as entidades que a pesquisa indique como pertinentes (tudo tem a ver com tudo, sim, mas o trabalho do pesquisador é dizer o que tem a ver com que, em que medida e de que maneira).

Que são arranjos? Séries (redes) de relações. De relações entre entidades. Que entidades? A pesquisa está a dizer. Mas (quase) nenhuma pesquisa parte de zero. $\mathrm{O}$ pesquisador encontra de entrada uma rede de conceitos, preceitos, teorias (e até tabus). E mal-entendidos, também. E entidades consagradas. O Estado, por exemplo: que entidade pode ser mais importante quando se fala em território do que o Estado?

As linhas fronteiriças, ou borders: são imaginárias? Bom, sim, no sentido em que não há uma linha que você possa ver ou tocar, para colocá-lo em termos sensoriais. Mas, estas linhas existem, existem muito, na medida em que os Estados esforçam-se por defini-las, mantê-las e fortalecê-las, e também na medida em que fazem parte, condicionam, determinam a vida das pessoas e o lugar e o status do conjunto de entidades 
que conformam o coletivo - a nação é um tipo de coletivo, e sem dúvida um dos mais importantes da modernidade. No entanto, mais uma vez, a nação não é pura, entrecruzase com outros coletivos, mas é reconhecível, e fundamental. $\mathrm{O}$ fato das fronteiras (tanto as fronteiras do mapa quanto outras possíveis) serem (umas mais e outras menos) porosas, não quer dizer que estas atuem menos ou sejam mais "imaginárias". Como agem? As fronteiras agem? Podemos considerar a fronteira como uma entidade que $f a z$ alguma coisa? A fronteira, que adota uma forma de rede com o fim de definir uma linha, é uma entidade composta de outras entidades como tratados, rios, exércitos, polícias, passaportes, contrabando e contrabandistas... e exerce influência em todos eles.

Note-se que a entidade Estado, que também está conformada por outras entidades que estabelecem relações entre si que as definem mutuamente, engloba ou comanda várias das entidades que mencionamos como constituintes da fronteira. Mas outras não provém do Estado. O Estado tal vez procure controlar a maior quantidade possível de entidades na hora de definir as suas fronteiras, mas nem sempre consegue. $\mathrm{O}$ antagonismo direto também não é a única opção para o Estado em relação a possíveis entidades rebeldes, desordenadas ou concorrentes, e pode, e de fato o faz, associar-se de formas surpreendentes com elas - com o provável objetivo de inseri-las numa ordem, na sua ordem.

Mas não só existe a ação do Estado (ou desde ou Estado) com relação às entidades do coletivo que podemos chamar de não estatais ou "sociedade civil” sobre ele. É claro, não consideramos o Estado e a sociedade civil como entidades puras e radicalmente distintas: o Estado é um subconjunto do coletivo nacional, e está conformado por antigos membros da sociedade civil (alguns deles com a capacidade de se deslocar rapidamente entre uma e outra destas duas dimensões). O Estado é capaz de exercer enormes mudanças no coletivo, mas a sociedade civil também tem a capacidade de transformar o Estado, ambas coisas acontecem.

A escala da ação espacial do Estado não se dá em termos de áreas, mas em termos da extensão e da qualidade das redes que ele consegue tecer. As áreas, ou seja, a contiguidade deste exercício, estaria definida pela densidade delas. As "rugosidades" espaço temporais que muitas vezes encontramos, e que muitas vezes nos surpreendem, podem, penso, visualizar-se mais facilmente se as entendemos como redes. 


\section{Estado, Território e Nação}

É verdade que a "imaginação", no sentido do sentimento de identidade e de simultaneidade, forma parte do nacional, como fica claro no popular livro do pesquisador Benedict Anderson que não é preciso citar. Aqui agiria o poder do polo sujeito da modernidade (a imaginação neste caso) para criar o objeto nação. Sim, a imaginação é muito poderosa. É performativa, até, no sentido em que orienta a ação. Mas, é claro, a nação é real demais como para ser um assunto de pura e simples imaginação — aliás porque, por definição, nada é nem puro nem simples. A imaginação nacional, como mostra Anderson, difunde-se através da literatura e dos mapas nacionais; mas, por que $a$ nação, e não outra coisa (a classe, por exemplo, como esperava Marx) é a fonte identitária mais forte, o protagonista coletivo estelar da modernidade? Boa pergunta, e muito antiga também. Não pretendo aqui dar conta dos debates acerca da questão nacional, mas penso que é possível perguntar-se como ela ficaria desde uma perspectiva relacional. Desconstruir e desmistificar a nação tem sido um trabalho importante por parte dos estudos pós-modernistas e pós-coloniais. No entanto, depois de desconstruir e desmistificar, talvez seja tempo de retornar ao compreender.

Estado e Nação não são a mesma coisa: são redes distinguíveis, mas têm infinitas interseções. São coisas-rede, sim, mas, de que tipo? Que faz delas distinguíveis e diferentes de outras coisas-rede? Os atores que compõem o Estado (que não são atores puros) são mais fáceis de distinguir: o exército, por exemplo; os burocratas; os prédios e lugares associados ao governo, as instituições. Mas e que faz a nação? A seleção de futebol, de certo é importante. A televisão, em geral, que faria nos dias de hoje o papel da literatura no livro de Anderson. A imaginação, o sentimento. É mais difícil de segurar, mas está aí. Os símbolos pátrios. A língua. O mapa nacional. A cultura, em geral. A lista parece ser muito mais longa, interminável. Muito difícil dar uma descrição tipo rede do sentimento nacional - por mais que em teoria seja possível. É um sentimento denso demais e abundante demais. No território, encontram-se o Estado e a Nação. Tanto o Estado quanto a nação precisam de um território. O que liga o Estado e a Nação, mesmo que possa ser de modo conflitante, é o território. É o que tem em comum. 


\section{O Território e a História da Geografia e da Cartografia}

Mapas e livros de geografia não só "registram" ou "refletem" a realidade ou o território, mas de certo participam, fazem mesmo diferença, modificam radicalmente a gama de possibilidades, intervém decisivamente nas condições de ação, do ser ou não ser, de pertencer ou não a um determinado grupo, de participar ou não, e de que maneira, em determinado arranjo histórico-geográfico. Em termos de formação territorial, geografia e cartografia são elementos chave para a apropriação, o controle, o planejamento e a construção de identidades.

A história da geografia e da cartografia apresentam um terreno sumamente interessante para pensar ao mesmo tempo a questão nacional, a questão regional e a questão territorial. A formação do território, a formação do Estado e a formação da nação são elementos diferenciáveis mais inseparáveis. Formação territorial - que, num sentido amplo, é importante dizer, não é sinônimo de "definição de fronteiras", mas constitui o processo de contínua redefinição, reorganização e redistribuição dos atributos, as identidades, as qualidades, as possibilidades, impossibilidades e limites de todas as combinações possíveis de lugares, áreas, circuitos e seres - está intrinsecamente ligada na história moderna à agência do Estado, a sua iniciativa e a sua afirmação, e fortemente associada à principal fonte de identidade do período, que não é outra que a nação. Pelas razões que forem - e a história da geografia e da cartografia provavelmente tenham muito a dizer e descobrir neste respeito - , o mundo está feito de Estados-nacionais territoriais.

Mas, como, exatamente, acontecem estas associações entre Estado, nação e território? Para começar, não devemos tratar cada um destes elementos como entidades discretas e independentes: sim, somos capazes de diferenciá-los e identificá-los, no entanto cada um deles está presente nos outros, numa espécie de tecido, cujo sentido e formação cabe ao pesquisador descrever e compreender.

A distribuição das instituições, da sua abrangência e efetividade, a definição das identidades —múltiplas, dinâmicas, complementares, concorrentes —, a ciência, gestão e organização das propriedades de uma miríade de entidades diversas e distantes (a geografia e a cartografia), são elementos constitutivos dos processos de formação territorial nacional estatal.

Estes processos chegam alguma vez a terminar e completar-se? Evidentemente não. No entanto, pode dizer-se sim, com certeza, que elementos fundamentais destes 
arranjos — fronteiras, por exemplo — tem, em geral, se estabilizado: mudar uma linha no mapa não é impossível — de fato vemos acontecer - , mas é em qualquer caso um exercício extremamente difícil e custoso em todo sentido para as pessoas envolvidas, envolvendo muitas vezes violência - o que não quer dizer que em determinados casos, tal vez em muitos casos, mudar uma destas linhas não seja uma decisão razoável ou em geral benéfica para os diretamente envolvidos.

Acredito que uma pesquisa e uma reflexão que considere ao mesmo tempo a história e a geografia das ciências geográficas, a história e a geografia da construção de identidades e a história e a geografia da definição de formas institucionais, pode ser chamada de pesquisa em formação ou história territorial. Propomos, nesse sentido, como método para a história da geografia e a geografia histórica, a descrição detalhada e simultânea dos processos espaço temporais de compreensão geográfica e cartográfica; de construção de instituições e ação institucional (Estatal); e da construção, afirmação e conflito de identidades.

A tarefa não parece nada simples, mas penso que pode ser feita, mesmo que pelo menos no começo - aos poucos. Em qualquer caso, não é tarefa para uma pessoa só, mas, como tudo, para uma comunidade de pesquisadores, que com sorte conseguirão ir encaixando às peças da nossa história territorial, nacional e continental.

\section{Território: Poder, Coletivo e Historicidade}

Onde estava a América antes da descoberta de Colombo? Não estava. E continuou não estando por vários anos mais, até acabar, aos poucos, depois de muitas polêmicas e dúvidas, fixando-se no mapa e deslocando a Espanha e Portugal das margens para o centro do mundo, do Novo Mundo. Isto não quer dizer que nesta parte do mundo não houvesse nada, mas que a Europa conseguiu inserir ela na sua ordem - começando por batizá-la. Onde andava o território antes dos geógrafos (médicos, poetas, exploradores, funcionários ou cronistas) vir a falar nele? Não andava! O território, para sê-lo, precisa ser apropriado - reivindicado, desejado, sonhado, disputado-, e para reivindicá-lo é preciso, muito ou pouco, mais algum tipo de conhecimento. O território, então, precisa de humanos, de grupos humanos, “unidades políticas”. Estas podem ser de diversas escalas, desde a familiar — ou mesmo a individual — até a global. Um dos tipos de agrupação humana mais importantes, talvez o tipo de unidade política fundamental da modernidade para efeitos territoriais de grande escala, é o Estado-nação. É possível 
pensar, sem dúvida, tanto uma territorialidade global quanto uma territorialidade familiar. Também, com certeza, em territorialidades não modernas. Mas, dada a importância dos Estados-nações na história moderna, é possível que tenha alguma utilidade tentar pensar a territorialidade estatal-nacional -incluso na medida em que entra em contato ou mesmo em conflito com territorialidades "outras".

Então, onde estava o território antes das unidades políticas? De novo, não estava. Vêm juntos. E com eles vem, nem antes nem depois, mas sempre junto, algum tipo de conhecimento. Mas conhecimento de quê? No caso dos Estados, em princípio, qualquer conhecimento que o possa adiantar em alguma coisa na difícil tarefa de definir/fazer um território, que é uma das exigências que o Estado, por definição, deve satisfazer. O território, aliás, é diferente aqui e lá (não é que "tudo é tudo": o Coletivo é, claro que sim, diferenciável, e as ciências prestam um grande serviço nesse sentido. Tudo tem a ver com tudo, sim, mas não da mesma forma nem no mesmo grau). Como seria possível construir um Estado e uma nação - e uma economia de mercado — sem saber o que há lá, o que não há, como chegar, ou se tem alguém? Ou, pelo menos, sem saber com certeza se de fato há um lá? Os governantes — os Estados costumam ter governantes — nem sempre tem tempo ou vontade de ir até lá para ver o que há. Muitas vezes, as distâncias e as incertezas são enormes. De fato, o governo é, em geral, uma coisa feita à distância. Mas como controlar lugares e pessoas distantes? Como fazê-los entrar na desejada ordem Estatal-nacional?

Certo tipo de conhecimentos, especialmente um que veio receber o nome de Geografia Moderna, podia, sem dúvida, prestar aqui um serviço considerável. Prestouo, de fato. Mas a Geografia Moderna, assim como o território, também não saiu do nada. É parte, fruto e condicionante do território. Tem uma história, é claro. Eis o argumento: a formação territorial e o conhecimento do território têm uma história. Melhor, são uma história - não duas. Ou que, para contar a história do território é preciso contar a história da ciência do território, e que para contar a história da ciência do território é preciso levar em conta os diversos atores - humanos e coisas - que dita ciência faz possíveis, reconhecíveis ou diferenciáveis. Ou que, assim como o conhecimento do território tem uma história, o território tem uma historicidade dada pelo estado da ciência do território. Não estou afirmando que as pessoas tenham que ir consultar o geógrafo antes de ir construir territorialidade, mas que os recursos que os estadistas têm para fazer o território nacional estão definidos, em grande parte, pela sua capacidade de adquirir e renovar seu conhecimento de entidades e dinâmicas ausentes e distantes. 
O que fazer com a pergunta “o que é o espaço?”: estudar formação territorial! As pessoas, seus parceiros sociais não humanos e a distribuição, as dinâmicas, os fluxos, as concentrações e as tendências dos seus vínculos. O território é resultado de um conjunto de associações que envolvem simultaneamente physis, logos e polis, o mundo, a ciência e a política, outorgando-se mutuamente historicidade (LATOUR, 2004b). O governo dos homens - o Estado moderno no caso - é o agente por excelência da gestão espacial, ou, dito de outra forma, da formação territorial. O Estado é o ator chave da configuração espacial do coletivo moderno. Sim, há múltiplos atores, e cada um faz sua parte, mais é o Estado o agente que em termos de formação territorial está obrigado a ter a iniciativa. O território não é dado, tem que ser conquistado — para bem ou para mal. Não é só o espaço "efetivamente dominado", pois a efetividade sempre tem um limite. Para chegar a ter agência espacial e gerar um território este tem que ser definido, desejado, reivindicado, desenhado, medido, calculado, enfim, conhecido.

A questão do poder é a de como os poucos e fracos conseguem dominar os muitos e fortes: como uns quantos escravizaram milhões, como um punhado de ingleses conseguem apoderar-se da Índia. Afirmar que o poder simplesmente "está na ponta do fuzil" é considerar apenas uma parte do problema - e um pouco de falta de imaginação. Para Sócrates — trata-se de um problema antigo - (Cf. o comentário de Bruno Latour acerca do Górgias de Platão, em: LATOUR, 2001. A tradução correta do subtítulo do livro seria "Ensaios sobre a realidade dos estudos da ciência” (Science Studies), e não “estudos científicos”. Esse lamentável equivoco de tradução — que não é o único — aparece em cada página do livro...) a chave se encontra nas demonstrações geométricas, nas leis impessoais e imutáveis do mundo exterior, que devem ser reimportadas pelos cientistas ao mundo social e fechar assim as discussões e manter afastada a incômoda e terrível massa de leigos. Para os sofistas, para aquilo bastava com a persuasão. Para Latour, não se trata de dominação, mas da construção do mundo comum.

Pode entender-se então o território como um nó de problemas, e tentar compreender as "grandes questões" - a modernidade, o eurocentrismo, a ciência, o Estado, a nação, a região - a partir do estudo empírico dos processos de formação territorial, tentando segurar na mesma explicação as propriedades dos atores não humanos, a história do conhecimento que faz possível definir essas propriedades e os processos de formação de unidades políticas. Determinismo ou possibilismo? O que define a história, as estruturas ou as vontades? O Mediterrâneo ou o Rei? Lenin ou a proletarização? A agência, desprende-se deste enfoque relacional, não é propriedade do 
sujeito nem do objeto, mas das associações: uma coisa é um Estado sem mapa e outra um Estado com - bons - mapas. O Estado mesmo, assim como os mapas e os territórios, são, em si, redes, diferenciáveis, mas interdependentes. O território é uma parte da Rede, e conserva boa parte de suas propriedades. Tem extensão, forma —relevo, topografia, rugosidade - e dinâmica. Tem história e historicidade. É uma "rede dentro da rede", definida por um tipo de estudo que consiste na observação de um processo conhecido como "formação territorial", que tenta dar conta das configurações espaciais relativas à formação de um corpo político, por meio do acompanhamento das interrelações entre os atores que o conformam, buscando identificar as incidências relativas destes - entre os quais, por exemplo, os famosos geógrafos, de campo e de gabinete.

Se estamos interessados na política da ciência e na ciência da política, a geografia pode ser um bom lugar de experimentação. No fim das contas, com muita frequência, os políticos interessaram-se pela geografia e os geógrafos interessaram-se pela política.

\section{Geografia Política}

A geografia tem padecido, tradicionalmente, de um certo complexo de inferioridade. Já foi acusada e chegou a considerar-se a si mesma teoricamente fraca e atrasada com respeito a outras ciências. Por exemplo, quando, finalmente, se decidiu abandonar o positivismo como paradigma e abraçar o marxismo, outras áreas das ciências humanas e sociais já se encontravam no debate sobre multiculturalismo e globalização. Surgiu uma espécie de tensão entre ambas as perspectivas: o materialismo dialético parece resolver o problema das dicotomias, pois coloca seus polos em interação (“contradição”) e, ao apresentar-se como "materialista”, permite neutralizar qualquer possível acusação de idealismo ou de pós-modernismo; no entanto, a sensação de novidade, mudança e desorientação que acompanhou o câmbio de milênio obrigou também a geografia a reconsiderar todos os seus pressupostos (não todos), reavaliar seus conceitos fundamentais (território, região, espaço e lugar) e discutir todos os "fins" (da modernidade, do território, do Estado-Nação, da história, do espaço, da geografia mesma... [depois virá a era da "reinvenção" de todos eles]), levando a dita disciplina a uma nova crise, uma das suas palavras favoritas. A geografia dividiu-se entre aqueles que consideravam que para mudar a realidade social era prioritário mudar a base material da mesma e aqueles que enfatizavam a necessidade prévia de uma mudança cultural ou psicológica. Isto é, mais um debate dicotômico, de certa forma equivalente ao debate 
clássico entre possibilismo versus determinismo. A geografia, em meu ponto de vista, tem sofrido, mais do que outras ciências, a pressão dicotomizadora da modernidade, que lhe exigiu definir-se como ciência natural ou social. Em outras palavras, a geografia, que tem sido por excelência a ciência das inter-relações entre elementos heterogêneos, sempre foi obrigada, pelas convenções modernas, a exprimir-se dicotomicamente.

O Brasil tem a sua própria tradição geográfica, que tem feito não poucos esforços por pensar sistematicamente acerca da disciplina, seus conceitos, seus métodos e seu papel no país e no mundo. Entre os pesquisadores que, de maneira mais significativa, têm contribuído na discussão conceitual da geografia, encontram-se Antonio Carlos Robert Moraes e Rogério Haesbaert, ambos autores de trabalhos sofisticados e instigantes (e, em meu ponto de vista, complementares). Moraes representa a tradição da geografia política, que define o território, basicamente, como a área dominada por um Estado e considera a formação territorial como o processo de progressiva apropriação espacial por parte daquele, não necessariamente em um sentido negativo, pois caberia ao Estado a função de melhorar as condições de vida das pessoas. Nesse sentido, uma ou outra abordagem teórica, para aquele autor, deve ser avaliada não tanto pela sua adscrição a uma ou outra tendência, mas pela sua praticidade, utilidade e efetividade nesse sentido (DANTAS; MORAES, 2010; MORAES, 2003, 2005, 2006, 2008).

Haesbaert, pela sua parte, concede "territorialidade" a todos os grupos sociais, caracterizando aquela exercida pelo Estado como mais homogeneizadora, na medida em que veiculadora da globalização; e a produzida pelas pessoas e grupos locais e regionais, como mais multicultural e diversificadora. Por outro lado, Haesbaert, com o fim de dar conta de fenômenos que entrelaçam lógicas de área com o funcionamento de circuitos (linhas e pontos), propõe o sugestivo conceito de "território-rede" (HAESBAERT, 2002, 2004, 2005).

Em meu ponto de vista - e seguindo, em parte, neste ponto, o citado geógrafo Joe Painter (2009) —, o território não seria, necessariamente, o oposto ou o contrário de rede (um arranjo dicotômico zonal versus um arranjo reticular), mas sim um tipo de rede que interage com e forma parte de outras redes, mas que, ainda assim, é reconhecível e diferenciável. O território, ou a "rede-território", se podemos dizer assim, seria, em minha opinião, o resultado da ação espacial do Estado em relação com outros tipos de espacialidade, especialmente os associados à formação de identidades coletivas.

Manter o Estado no centro da definição de território não tem unicamente a vantagem de conservar o vínculo com a tradição da geografia política e as suas teorias e 
técnicas de análise da distribuição espacial do poder — boa parte delas desenvolvidas com base na observação das práticas espaciais dos Estados -, mas parece-me que seja apenas uma medida prática e realista, dado que é indiscutível que esta instituição tem sido um dos principais agentes produtores de territorialidade, se não o principal. A chave, considero, é a de não reificar os Estados, nem os territórios, nem as identidades, ou seja, não tomar estes entes como coisas unitárias e homogêneas, mas como redes entrelaçadas. Da mesma forma, deste ponto de vista, as áreas, as superfícies, as linhas limítrofes, as regiões e os lugares, assim como os "sujeitos" e os "objetos", seriam também efeitos, ou, melhor, estados, de diferentes tipos de redes, da distribuição, da concentração e da regionalização de fluxos de inter-relações entre entidades diversas e heterogêneas.

\section{Considerações Finais}

Como fica aqui a geografia, que lutou tanto para ser considerada moderna, muitas vezes definindo-se como "social" como estratégia para isto? Apesar de em geral ser possível localizar em algum lugar da polaridade sujeito-objeto caraterística da modernidade a maioria das posturas intelectuais e as declarações metodológicas dos geógrafos emitidas nas introduções dos seus textos, a geografia desfruta de uma grande riqueza conceitual e tem uma longa tradição e treinamento em pensamento relacional, assim como em técnicas analíticas e descritivas de inter-relações complexas. Considero que estas sejam vantagens.

\section{NOTAS}

* O presente artigo corresponde a reflexões iniciadas desde a graduação. Uma versão inicial do mesmo pode encontrar-se na minha tese de doutorado "A Nueva Geografía de Colombia de Francisco Javier Vergara y Velasco (1901) [1902]”, defendida em 2015 e financiada com bolsa da CNPq. A versão final foi elaborada como parte do meu estágio pós-doutoral no Instituto de Geografia da Universidade Nacional Autónoma do México, graças à bolsa DGAPA de dita instituição (2016-2018).

\section{REFERÊNCIAS BIBLIOGRÁFICAS}

AGNEW, John. Making political geography. London: New York: Arnold; Distributed in the United States of America by Oxford University Press, 2002.

BLOOR, David. Anti-Latour. Studies in History and Philosophy of Science Part A, v. 30, n. 1, p. $81-$ 112, mar. 1999a. 


\section{9:}

Reply to Bruno Latour. Studies in History and Philosophy of Science Part A, v. 30, n. 1, p. 131-136, mar. 1999b.

DANTAS, Monica Duarte; MORAES, Antonio Carlos Robert (Org.). Nação e território: ideologias geográficas na formação histórica do Brasil. Fórum rumos da cidadania Campos de Jordão, São Paulo, 2009. São Paulo: Instituto Prometheus de Estudos Ambientais, Culturais e Políticos, 2010. p. 59-70.

DOLWICK, J. S. "The Social” and Beyond: Introducing Actor-Network Theory. Journal of Maritime Archaeology, v. 4, n. 1, p. 21-49, 2009.

GOULD, Stephen Jay. The mismeasure of man. Rev. and expanded ed. New York: Norton, 1996.

HAESBAERT, Rogério. Da desterritorialização à multiterritorialidade. In: X ENCONTRO DE GEÓGRAFOS DA AMÉRICA LATINA, 2005, São Paulo. Anais... São Paulo: Universidade de São Paulo, 2005. p. 6774-6792.

O mito da desterritorialização: do "fim dos territórios" à multi-territorialidade. Rio de Janeiro: Bertrand Brasil, 2004.

Territórios alternativos. Niterói: EdUFF, 2002.

LATOUR, Bruno. A esperança de Pandora: ensaios sobre a realidade dos estudos científicos. Bauru, SP: EDUSC, 2001.

Cognição e visualização: Pensando com olhos e mãos. Terra Brasilis (Nova Série). Revista da Rede Brasileira de História da Geografia e Geografia Histórica, n. 4, 13 fev. 2015. Tradução David Palacios. . Disponível em: <http://terrabrasilis.revues.org/1308>.

. For David Bloor... and Beyond: A Reply to David Bloor's' Anti-Latour'. Studies in History and Philosophy of Science Part A, v. 30, n. 1, p. 113-129, mar. 1999.

La cartographie des controverses. Technology Revierw, p. 82-83, 2007.

On recalling ANT. The Sociological Review, v. 46, n. S1, p. 15-25, 1998.

2004a.

Políticas da natureza. Tradução Carlos Aurelio Mota de Souza. Bauru, SP: EDUSC,

Politics of Nature. Tradução Catherine Porter. Cambridge: Harvard University Press, $2004 \mathrm{~b}$.

Reagregando o Social. Salvador, BA: EDUFBA, 2012.

Reassembling the Social. Oxford; New York: Oxford University Press, 2005.

Science in Action. Cambridge, Mass.: Harvard University Press, 1987.

We Have Never Been Modern. Tradução Catherine Porter. Cambridge, Mass.: Harvard University Press, 1993.

LAW, John; MOL, Annemarie. Situating technoscience: an inquiry into spatialities. Environment and Planning D: Society and Space, v. 19, n. 5, p. 609-621, 2001.

MORAES, Antonio Carlos Robert. A afirmação da territorialidade estatal no Brasl: uma introdução. In: LEMOS, Amália Inês Geraiges de; SILVEIRA, Maria Laura; ARROYO, Mónica 
(Org.). Questões territoriais na América Latina. Coleção Edição e Distribuição Cooperativa. Por uma Geografia Latino-Americana. São Paulo: CLACSO/ FFLCH-USP, 2006.

Formação territorial e políticas ambientais no Brasil. In: RIBEIRO, Wagner Costa (Org.). . Patrimônio ambiental brasileiro. São Paulo: Edusp - Imprensa Oficial, 2003. p. 79-87.

Território e história no Brasil. São Paulo: Annablume, 2008.

Território, poder e justiça: comentários a partir da experiência brasileira. In: KRITSCH, Raquel; RICUPERO, Bernardo (Org.). Força e legitimidade: novas perspectivas? São Paulo: Associação Editorial Humanitas : NADD-Núcleo de Apoio à Pesquisa sobre Democratização e Desenvolvimento-USP, 2005. p. 113-129.

MURDOCH, Jonathan. The spaces of actor-network theory. Geoforum, v. 29, n. 4, p. 357-374, nov. 1998.

NOVEMBER, Valérie; CAMACHO-HÜBNER, Eduardo; LATOUR, Bruno. Entrando em território arriscado. Terra Brasilis (Nova Série). Revista da Rede Brasileira de História da Geografia e Geografia Histórica, n. 2, 21 jun. 2013Tradução David Palacios. Disponível em: $<$ http://terrabrasilis.revues.org/903>.

PAINTER, Joe. Territoire et réseau: une fausse dichotomie? = Territory and network: a false dichotomy? In: VANIER, Martin (Org.). Territoires, territorialité, territorialisation: Controverses et perspectives. Rennes: Presses Universitaires de Rennes, 2009. p. 57-66. Disponível em: <http://dro.dur.ac.uk/5276/1/5276.pdf?DDC52+DDD14+dggojmp>.

Territory-network. In: ASSOCIATION OF AMERICAN GEOGRAPHERS ANNUAL MEeting, 2006, Chicago. Anais... Chicago: Durham Research Online, 2006. Disponível em: <http://dro.dur.ac.uk/8537/1/8537.pdf>.

RAMÍREZ PALACIOS, David Alejandro. A Nueva Geografía de Colombia de Francisco Javier Vergara y Velasco (1901) [1902]. 2015. 2 v. f. Tese de Doutorado - Departamento de Geografia Humana - Universidade de São Paulo, São Paulo, 2015. Disponível em: <http://www.teses.usp.br/teses/disponiveis/8/8136/tde-09102015-135247/pt-br.php>.

Élisée Reclus e a geografia da Colômbia. 2010. Dissertação de Mestrado - Universidade de São Paulo, 2010. Disponível em: <http://www.teses.usp.br/teses/disponiveis/8/8136/tde06102010-093308/pt-br.php>.

Jamais fomos [nem geógrafos nem cartógrafos] modernos: ANT, história da geografia, história da cartografia e formação territorial. In: CIRCULAÇÃO DAS IDÉIAS E HISTÓRIA DOS SABERES GEOGRÁFICOS: HIERARQUIAS, INTERAÇÕES E REDES, 2014, Rio de Janeiro. Anais... Rio de Janeiro: [s.n.], 2014. p. 15-17.

VENTURINI, Tommaso. Building on faults: How to represent controversies with digital methods. Public Understanding of Science, v. 21, n. 7, p. 796-812, 5 dez. 2010 a.

Diving in Magma: How to Explore Controversies with Actor-Network Theory. Public Understanding of Science, v. 19, n. 3, p. 258-273, 1 maio 2010 b.

WHATMORE, Sarah. Hybrid Geographies. London; Thousand Oaks, Calif.: SAGE Publications, 2002. 